Área Abierta. Revista de comunicación audiovisual y publicitaria ISSN: 2530-7592 / ISSNe: 1578-8393

\title{
El espacio como fuente de significación en la construcción discursiva del film Arsénico por compasión
}

\author{
Silvia Magro Vela ${ }^{1}$, Belén Puebla Martínez²y Rainer Rubira García ${ }^{3}$
}

Recibido: 6 de junio de 2019 / Aceptado: 21 de septiembre de 2019

Resumen. El presente texto aborda el análisis del marco espacial en el ámbito del relato fílmico. A partir de diferentes propuestas teóricas se realiza una investigación de naturaleza hermenéutica sobre la representación del espacio, su configuración y su sentido dentro de la obra cinematográfica. El caso de estudio seleccionado es Arsénico por compasión (Arsenic and Old Lace, Frank Capra, 1944), considerada un clásico del género de la comedia. El análisis del discurso es la técnica seleccionada para conseguir los siguientes objetivos: reconocer los distintos tipos de espacio que aparecen y ayudan a la construcción del discurso fílmico en tanto unidad de sentido; reflexionar sobre el espacio como escenario, el espacio construido y el espacio significado, haciendo énfasis sobre el espacio omitido como una forma más de expresión fílmica. Por lo que el espacio se presenta como un ente vivo, dinámico, que juega un papel crucial en la construcción semántica.

Palabras clave: espacio; análisis del discurso fílmico; construcción de sentido; Arsénico por compasión; Frank Capra

\section{[en] Space as a Source of Meaning in the Discourse Construction of the Film Arsenic and Old Lace}

\begin{abstract}
The present text deals with spatial framework analysis in the context of film narration. Based on different theoretical proposals, a hermeneutic research is carried out on the representation of space, its configuration and its meaning within the cinematographic work. The case study selected is Arsenic and Old Lace (Frank Capra, 1944), which is considered a classic of the comedy genre. The film discourse analysis is the technique selected to achieve the following objectives: recognizing the different types of space which appear and help on the film discourse construction as a unit of meaning and emphasizing omitted space as one more form of film expression. Thus, space is presented to us as a living, dynamic entity that plays a crucial role in its semantic construction.
\end{abstract}

Key words: Space; Film Discourse Analysis; Meaning Construction; Arsenic and Old Lace; Frank Capra

Sumario. 1. Introducción. 2. Marco teórico. 3. Objeto de estudio y metodología. 4. Resultados. 5. Conclusiones. 6. Bibliografía.

\footnotetext{
1 Universidad Rey Juan Carlos (España)

E-mail: silvia.magro@urjc.es

2 Universidad Rey Juan Carlos (España)

E-mail: belen.puebla@urjc.es

3 Universidad Rey Juan Carlos (España)

E-mail rainer.rubira@urjc.es
} 
Cómo citar. Magro Vela, Silvia; Puebla Martínez, Belén y Rubira García, Rainer (2020). El espacio como fuente de significación en la construcción discursiva del film "Arsénico por compasión". Área Abierta. Revista de comunicación audiovisual y publicitaria 20 (1), 27-38, https://dx.doi.org/10.5209/ arab.64610

\section{Introducción}

En la naturaleza intrínseca y esencia de cualquier relato, sea del tipo que sea, el espacio supone uno de los pilares fundamentales en cuanto a la lógica narrativa; una historia atiende a un marco espacio-temporal concreto sin el que no sería posible y en el que, si se modificara cualquier variable, se vería modificada también la idiosincrasia de la misma.

Desde el origen de las representaciones artísticas el individuo se ha preocupado de la construcción de este elemento para asemejarlo a lo real. En palabras de Cuadrado:

La perspectiva fue algo más que un planteamiento técnico de una nueva forma de representación, fue materialización del ideal ilusionista de la imagen, aquel que nos lleva a experimentar la pintura como un espacio más allá del que nos rodea, un espacio que invita a entrar como si de una puerta se tratara. Este ideal vertebra el arte y las tecnologías de la imagen a lo largo de más de quinientos años (Cuadrado, 2014: 143-144).

De esta manera, ya durante el Renacimiento la perspectiva era una de las variables que hacían de una pintura el retrato verosímil de una realidad representada. La fotografía también se preocupó por dotar de profundidad a sus imágenes para convertirlas en ventanas simuladas de esa misma realidad. Las representaciones escénicas, como el teatro, se servían del espacio para la narración de sus obras; como lo harán posteriormente el cine, la televisión, los videojuegos, etc.

Recogiendo la idea de Burch (1999: 173) en el cine primigenio de los hermanos Lumière se puede observar "una reproducción perfecta de las reglas de la perspectiva tal y como las codificó Alberti. Pero [...] no podemos hablar de una hegemonía de este tipo de imagen sobre el cine de los comienzos".

Por tanto, algo que parte desde la base como es la construcción del espacio narrativo, y la posterior percepción del mismo por el espectador, se convierte en arduo trabajo que se servirá de herramientas y códigos complejos para la transmisión de información acerca de la propia trama, columna vertebral del relato.

Sin embargo, no está en los límites de este trabajo hacer un análisis de la combinación espacio-tiempo. Al ser una obra basada en el estilo empleado en las representaciones teatrales, la variable tiempo tiene una función narrativa delimitada prácticamente por la ubicuidad del relato en un momento concreto.

Partiendo de esta idea en la que la configuración del espacio es un eje sobre el que orbita gran parte del sentido de la obra, se pretende estudiar la construcción del espacio en el ámbito cinematográfico. Dentro del ingente número de títulos enmarcados en la producción fílmica, el análisis se centrará en el film Arsénico por compasión (Arsenic and Old Lace. Frank Capra, 1944). 


\section{Marco teórico}

El marco espacial dentro del relato fílmico es un componente complejo, como sucede con el resto de elementos narrativos, pues su construcción es notablemente diversa a la de la narrativa literaria. En el caso literario el espacio se describe mediante el uso de palabras únicamente; es a partir de esas palabras cuando el lector completa la configuración del espacio mediante un proceso mental. En esta línea se encuentran las ideas de Chatman (1990: 190) cuando se refiere al espacio literario como "abstracto" porque es una "construcción mental" creada por ese lector al que se alude.

Por el contrario, en el caso del relato fílmico la construcción del espacio es un compendio de imágenes mostradas a través de la cámara, movimientos, gestos y expresiones de los personajes, diálogos, iluminación, música, sonidos, montaje... y además le es presentada construida completamente al espectador, sin dejar que los procesos cognitivos se encarguen de unir todos los elementos en una concepción individualizada.

En este sentido, debido a la complejidad expuesta acerca de la conformación del espacio, su análisis no es asunto baladí; presenta amplias dificultades y se aproxima más a las representaciones escénicas, en general, y al teatro, en particular. Las relaciones entre ambos medios son evidentes y, sin ser el objeto de estudio de este texto, cabe mencionar la existencia de diversas propuestas teóricas al revisar las teorías cinematográficas. Sin pretender una revisión sistemática de las mismas, se puede mencionar a Guarinos (1992) que recoge un detallado resumen sobre esta idea.

Así, Hernández Les establece (1993: 71) que "el cine adapta del teatro una forma de expresión, más que un relato, mientras que de la novela se adapta un relato más que una forma de expresión" y para Mitry (1978, II: 414) "la imagen cinematográfica desempeña exactamente el papel que en el teatro cumple el verbo". Pero retomando el concepto de la espacialidad y la estrecha relación en algunos aspectos entre cine y teatro, Guarinos (1996: 81) resume que "mientras el espacio teatral es dado por completo en la escena, el fílmico viene creado por el espacio físico filmado, en la relación de la cámara con él, el montaje...”. El espectador de teatro mantiene una visión permanente de todo el espacio que engloba la narración, así como de los personajes o acciones simultáneas que se puedan estar desarrollando.

No hay que olvidar que el cine se ha guiado durante un amplio periodo de tiempo por unas pautas de representación cercanas a artes escénicas más antiguas — como el teatro- que han dado como resultado términos como son el "modo de representación institucional" (MRI) utilizado por Burch (1999) o el modelo "Clásico" al que alude González Requena (1996) al hablar de los tres modos de representación —clásico, manierista y postclásico- Entre las características de esta forma de representación está la frontalidad de las imágenes y una pretendida naturalidad o transparencia. Sobre esta "transparencia escénica" reflexiona Xavier:

Tudo neste cinema caminha em direção ao controle total da realidade criada pelas imagens - tudo composto, cronometrado e previsto-. Ao mesmo tempo, tudo aponta para a invisibilidade dos meios de produção desta realidade. Em todos os níveis, a palavra de ordem é "parecer verdadeiro"; montar um sistema de represen- 
tação que procura anular a sua presença como trabalho de representação (Xavier, 2005: 41). ${ }^{4}$

Sin embargo, al retomar la idea de la visión del espacio por parte del espectador, el relato fílmico se encuentra más cerca del literario que del teatral. El espectador de cine $y$, posteriormente, de cualquier medio que utilice la pantalla para su exhibición, percibe $\mathrm{y}$, en definitiva, descubre el espacio a través de una intervención externa. Existe una mediación de la mirada que es dirigida por la intención del narrador y que se sirve de herramientas como los tamaños de plano o el montaje para la fragmentación y posterior recomposición del espacio. Para Bordwell y Thompson (1995: 163) "La puesta en escena contiene un gran número de factores puramente espaciales y temporales para guiar nuestras expectativas y, por lo tanto, condicionar nuestra visión de la imagen".

La imagen proyectada en una pantalla es bidimensional y plana, sin embargo, la puesta en escena hace que la percepción espacial sea tridimensional, de manera análoga al espacio real que nos rodea. Según Aumont, Berganla, Marie y Vernet (2008) las razones de esa percepción tridimensional tomada a partir de una imagen que no lo es, provienen de las leyes ópticas y del código de la perspectiva. Mediante estos artificios el espectador cree tener delante una imagen equivalente a la realidad. Siguiendo con esta argumentación Bordwell y Thompson (1995: 164) explican cómo "el cineasta utiliza la puesta en escena para guiar nuestra atención por la pantalla, condicionando nuestra percepción del espacio representado y poniendo de relieve ciertas partes de él".

Es preciso puntualizar que el presente texto se ocupa del espacio fílmico que Casetti y di Chio (2017: 122) definen como "el espacio construido y presentado en la pantalla" o también en palabras de Rohmer "no tanto el espacio filmado como un espacio virtual sugerido al espectador" (en Rollet, 2014: 70); valiéndose para ello con la ayuda del "espacio pictórico" y del "espacio arquitectónico". Este espacio, por tanto, concuerda con el espacio diegético de la historia narrada y se aceptan como tal las características propias de ese mundo posible presentado en la narración.

La construcción de ese espacio se compone a su vez de dos espacios, el espacio in y el espacio off; o lo que es lo mismo, el espacio del campo y el espacio fuera de él. El primero de los dos, es el espacio compuesto por todos aquellos elementos que el espectador puede ver en pantalla. En el segundo caso, el espacio fuera de campo será todo lo que forme parte de esa construcción espacial pero que no está a la vista del espectador en la pantalla.

En lo que refiere a este espacio off o fuera de campo, su naturaleza infinitamente más compleja que en el caso del espacio in o en campo, hace que sea necesario clarificar algunos principios para su análisis o discusión. Como define Burch:

Se divide en seis 'segmentos': los confines inmediatos de los cuatro primeros segmentos están determinados por los cuatro bordes del encuadre: son las proyecciones imaginarias en el espacio ambiente de una 'pirámide' (aunque esto sea evidentemente una simplificación). El quinto segmento no puede ser definido con

Traducción realizada por los autores: "Todo en este cine camina hacia el control total de la realidad creada por las imágenes — todo compuesto, cronometrado y previsto-. Al mismo tiempo, todo apunta a la invisibilidad de los medios de producción de esta realidad. En todos los niveles, la consigna es 'parecer verdad'; montar un sistema de representación que busca anular su presencia como trabajo de representación". 
la misma (falsa) precisión geométrica, y sin embargo nadie pondrá en duda la existencia de un espacio-fuera-de-campo 'detrás de la cámara' distinto de los segmentos alrededor del encuadre, [...]. Por fin, el sexto segmento comprende todo que se encuentra detrás del decorado (o detrás de un elemento del decorado) [...] (Burch (1970: 26).

Al hilo de las definiciones de Burch, resulta interesante hacer referencia a cómo Gómez Tarín (2003) considera ese fuera de campo como un contexto del espacio en campo o in que se encuentra enmarcado dentro de un fragmento espacio-temporal. Berganla, Marie y Vernet (2008) en su esfuerzo por concretar acerca del fuera de campo, hace alusión al "conjunto de elementos - personajes, decorados, etcéteraque, aun no estando incluidos en el campo, sin embargo, le son asignados imaginariamente, por el espectador, a través de cualquier medio". El vínculo entre el espacio visible (in) y el invisible (off) es innegable, pues la existencia de uno está supeditada a la del otro y en estrecha relación con la porción de espacio narrativo encerrada dentro del cuadro. Aumont, Berganla, Marie y Vernet concluyen así:

[...], a pesar de que hay entre ellos una diferencia importantísima (el campo es visible, el fuera de campo no), se puede considerar en cierto modo que campo y fuera de campo pertenecen ambos, con todo derecho, a un mismo espacio imaginario perfectamente homogéneo que denominamos espacio fílmico o escena fílmica (Aumont, Berganla, Marie y Vernet 2008).

La configuración del espacio, y por consiguiente de su análisis, conlleva la interactuación de numerosos elementos que conforman ese marco espacio-temporal de cualquier relato cinematográfico. Más allá del espacio visible e invisible, la construcción sonora y la iluminación hallan su función configuradora del mismo.

Ese espacio mostrado a través de la pantalla no es fijo, sino cambiante. La cámara funciona como una mira telescópica que se va moviendo para recorrer los rincones y cavidades del espacio diegético. Es así como el espacio adquiere lo que Casetti y di Chio (2017) denominan "cualidad plástica" que viene dada por el movimiento, convirtiendo al espacio en un elemento moldeable que se va adaptando y modificando según va apareciendo y desapareciendo en esa mira telescópica que es la cámara.

Finalmente, el espacio responde a una función de creación de significados en diferentes aspectos. En este sentido, el espacio no solo formará parte en la disposición espacial de la narrativa, sino que la ayudará en su dotación de sentido. Neira (1998: 377) establece que "la teoría literaria ha indicado ya cómo los espacios y los subespacios pueden semiotizarse, es decir, convertirse en signo ya sea de los personajes, de las relaciones que se establecen, etc.". En el caso de los personajes, también se puede dar la no adecuación a un espacio que habita, siendo antinatural el espacio y los personajes que conviven en él. Este puede ser el uso que se da en comedias donde se presenta a personajes fuera de su contexto para generar la burla o el gag cómico.

\section{Objeto de estudio y metodología}

Si se analiza la nutrida filmografía del director, Frank Capra, Arsénico por compasión se encuentra entre títulos como Sucedió una noche (It Happened One Night. 
Frank Capra, 1934) o ¡Qué bello es vivir! (It's a Wonderful Life. Frank Capra, 1946) sobre los que mucho se ha escrito.

Arsénico por compasión es una adaptación cinematográfica de una obra teatral de la cual Capra obtuvo los derechos del guión prácticamente abalanzándose sobre el escenario al termirar la representación. El argumento se basa en la historia de un crítico teatral de reconocido prestigio, Mortimer Brewster, tras años de rechazo del matrimonio, se casa por sorpresa. Antes de emprender su viaje de luna de miel, decide despedirse de sus dos tías solteras quienes lo han criado. A partir de este momento, la verdadera identidad de sus adorables tías se hace visible: acaban con la vida de ancianos solitarios por compasión; con una técnica tan sencilla como eficaz, vertiendo arsénico en el vino que les ofrecen como bienvenida.

Gallego-Díaz (2015) recupera las palabras de las memorias del director para explicar que fue "una corazonada" y que "es creatividad intentando decirte algo". Además, el film consiguió contar con parte importante de los actores que interpretaban la obra en Broadway, como fue el caso de las actrices que daban vida a las tías Brewster, Martha (Jean Adair) y Abby (Josephine Hull).

En cuanto al tema de la película, se narra una historia bastante enrevesada contada en clave humorística que hace que sea una comedia hilarante a pesar de estar dotada de un trasfondo macabro — pues la muerte está presente de principio a fin-. Por otro lado, temas no menos sombríos como el asesinato, la delincuencia e incluso la demencia en sus personajes, completan la propuesta temática sobre la que se configura el relato.

\subsection{Objetivos de la investigación}

El objetivo principal de este estudio se centra en analizar cómo la representación y la distribución de los elementos en el espacio diegético realzan el uso del lenguaje cinematográfico mediante la herencia directa de su predecesor, el relato teatral.

En segundo lugar, observar si la configuración del espacio fuera de campo enriquecido con numerosos elementos puede establecerse como una herramienta destacada para la creación de ideas que sirvan de apoyo a la trama narrativa.

Para finalizar, como último objetivo propuesto, se busca analizar a los personajes; comprobar si con sus características y sus conflictos transforman el espacio fílmico en algo propio, convirtiéndolo en un espacio simbólico que representa en esencia lo que son o lo que sucede.

\subsection{Metodología de análisis}

Para llevar a cabo la investigación se realizará un análisis del discurso del texto fílmico como lo entienden Casetti y di Chio (2017) respecto a la representación del espacio. Se tomará un único relato fílmico al entender el análisis del espacio como un trabajo complejo y a la vez extenso, descartando así el poder realizar una comparativa con otros textos audiovisuales que, sin embargo, queda abierta como línea de trabajo para futuras investigaciones.

Se considera así, que el objeto didáctico del estudio justifica un análisis basado en una descripción formalista y detallada, si bien se buscará compensar este aspecto introduciendo la interpretación a los resultados obtenidos. 
Se pretende descubrir el modo de articulación espacial de la pieza audiovisual, su configuración y su funcionamiento dentro de la narrativa del relato. En este sentido se utilizará, como se ha mencionado anteriormente, la película Arsénico por compasión y se seguirán las líneas propuestas por los autores Casetti y di Chio (2017) en relación al campo y fuera de campo.

También se atenderá al uso y la distribución de los elementos en el espacio para establecer si existe intermedialidad entre el relato fílmico y el teatral, como apuntaban los estudios sobre el tema que proponen autores como Guarinos (1996), entre otros.

Finalmente, Neira (1998) sugiere el uso del espacio para aportar significación en cuanto a conflictos surgidos de la trama o personajes. Se observará si el espacio cambia o adquiere características propias de los personajes que lo habitan.

\section{Resultados}

Los datos obtenidos del análisis en relación al estudio del marco espacial del texto fílmico se presentan distribuidos y separados en cuatro categorías; de este modo, se atiende por separado al espacio como escenario, al espacio construido y al espacio significado.

\subsection{El espacio como escenario}

Uno de los aspectos más llamativos durante el visionado del film es el reducido número de localizaciones utilizadas para el desarrollo de la totalidad de la acción. La casa familiar es el eje central en este sentido, con sus diversos espacios como son la cocina, el salón, la parte superior y el sótano. A pesar de ser una localización única, Capra consigue una hábil fragmentación del espacio que aporta ritmo a la trama. Dentro del mismo espacio, en el caso del salón, se desarrollan acciones en diferentes rincones con relevancia para la historia, como por ejemplo la zona del ventanal que acoge el arcón o la escalera. En este sentido como apunta Breijo (1992: 42) "Capra ataca frontalmente los convencionalismos partiendo de las armas más básicas de un director: la cámara, la mirada".

La distribución de los personajes dentro del espacio refleja las convenciones establecidas en las representaciones escénicas. Este aspecto se aprecia en diferentes secuencias a lo largo de todo el film, en las que prima la sensación de cuarta pared propia del teatro. Por otro lado, los personajes se amontonan en torno a un mismo espacio reducido en el que es frecuente ver entre cuatro y seis personajes a un tiempo. Las secuencias acontecidas en el salón donde Mortimer Brewster es maniatado por su hermano Jonathan y el Dr. Einstein o con las tías Martha y Abby cuando reciben a un nuevo y posible "inquilino" también en la misma estancia.

De la misma manera, es conveniente hacer referencia a los tamaños de plano que predominan durante la trama. Estos son generales, americanos, medios y primeros planos, siendo los generales y americanos abundantes. Así pues, se encuentran similitudes a películas coetáneas, con una planificación básica en la misma línea. Esto recuerda a la distribución de las escenas teatrales, en las que el espectador tiene una visión completa del espacio, de la acción en desarrollo y de los personajes ubicados en la escena. Es así como el espectador no pierde la conciencia de que está asistiendo 
a una representación de la realidad y no a la realidad. Esta idea la define perfectamente Pérez Bowie (2004: 584) al afirmar que “... el universo que presentan estas comedias, al igual que el ofrecido por la pantalla, está siempre envuelto en un nimbo de irrealidad que hace que los espectadores lo experimenten como una dimensión inaccesible desde su universo cotidiano".

Un último aspecto a considerar es la disposición de la cámara y la distancia existente con la acción: queda patente desde el comienzo la tendencia neutral en gran parte de las secuencias, si bien es cierto que esta neutralidad se rompe con la introducción de elementos expresivos que se analizarán posteriormente. Con estas características, el relato fílmico se halla enmarcado dentro del modelo de representación institucional (MRI) al que se aludía en relación a Burch.

Este hecho se repite a lo largo de todo el texto audiovisual, lo que contradice la apreciación acerca de las adaptaciones de textos teatrales a películas que hace Bazin (1966: 255) donde "la preocupación fundamental del cineasta parecía ser la de camuflar el origen teatral del modelo, adaptándolo, disolviéndolo en el cine". En el caso concreto de Capra en Arsénico por compasión no se aprecia esta intención. Como se desgranará en epígrafes posteriores, sí se introducen herramientas propias del lenguaje cinematográfico como son la utilización de la iluminación y la introducción de movimientos de cámara con fines expresivos.

\subsection{El espacio construido}

Una vez definidos en el marco teórico los conceptos de espacio in - en campo- y off - fuera de campo_-, así como los segmentos que componen ese espacio invisible, es preciso atender a su uso en el título seleccionado. La configuración del espacio visible a lo largo de todo el metraje, como se dejaba entrever en el epígrafe precedente, se limita a localizaciones concretas que son asumidas por parte del espectador desde el principio. Este hecho cierra la historia en un espacio muy delimitado y concentrado que, además, es prácticamente interior en su mayoría.

La muerte, epicentro de la narrativa, es el principal ausente para el ojo del espectador, mas no para la narración. No hay un fotograma en el que se muestre con crudeza un cuerpo yaciendo inerte. No obstante, la muerte está presente de forma casi palpable a lo largo del relato.

El arcón situado bajo el ventanal del salón de la casa Brewster, que funciona como ataúd, se convierte en un elemento imprescindible y central de la trama: es el contenedor de esa muerte que permanece fuera del campo visual del espectador y aun así latente en todo momento de principio a fin del texto fílmico. Casi todos los personajes levantan la tapa en algún momento para mirar en su interior; incluso el Dr. Einstein se introduce dentro, dando como resultado una imagen muy expresiva. Este elemento conformante de la puesta en escena acaba alcanzando una personalidad cuasi propia, convirtiéndose en un personaje más de la narración. En no pocas ocasiones se hace referencia a su contenido de forma verbal o mediante las miradas que se proyectan más allá del cuadro — en esos segmentos conformantes, pero no visibles - sin embargo, nunca se ve el interior. Cada vez que envenenan a un caballero, lo guardan en el arcón mencionado y realizan un enterramiento en lo que llaman el "Canal de Panamá". Es Teddy Brewster, el hermano con trastornos mentales, quién convencido de ser Roosevelt -Franklin D. Roosevelt, el presidente de Estados Unidos entre 1933 y 1945 — , se encarga del entierro de "las víctimas de 
la fiebre amarilla". Abbey y Martha se visten de luto riguroso y se celebra el ritual. El espectador no visualiza ni las tumbas, ni los cadáveres, pero sí se deja entrever la silueta del último fallecido en lo que podría ser una marcha fúnebre y los preparativos para el sepelio. Toda una secuencia que se apoya en el uso de la iluminación para crear un ambiente que define, sin enseñar nada, el concepto principal de la trama.

Ese espacio aludido como el "Canal de Panamá" no es más que el sótano. De nuevo, un habitáculo del que no se sabe prácticamente nada: se desconoce el tamaño de ese lugar, su aspecto, los objetos que se distribuyen en su interior, etcétera. A pesar de no verlo físicamente asistimos a una conversación entre los dos criminales, Jonathan y el Dr. Einstein, sentados en las escaleras de acceso al lugar donde sobre sus caras se proyecta la sombra de Teddy, trabajando en la excavación de una nueva tumba.

De esta manera, se percibe cómo en la construcción del espacio que se alza más allá del horizonte de la mirada del espectador intervienen diferentes elementos como el sonido o la iluminación. Burch (1999: 184) indicaba que existía "Otro aspecto esencial de esta gradual 'conquista del espacio': el dominio de la iluminación”.

Por tanto, la cámara o la iluminación se convierten en parte constitutiva de ese espacio que no aparece recogido dentro del encuadre. De la misma manera que las luces y las sombras transmiten los volúmenes y las formas del espacio que se proyectan más allá de la construcción del espacio in, aportando continuidad espacial al espectador, la cámara lo hace mediante el movimiento. Debido a la fragmentación propia del lenguaje audiovisual, y por ende cinematográfico, se necesita una constante (re)construcción del espacio narrativo. La cámara nos guía por ese espacio acompañándonos en ese recorrido a través de sus movimientos. Así el espacio no es estático, sino un elemento dinámico que permanece vivo durante toda la obra audiovisual. En palabra de Casetti y di Chio (2017: 122) “... cuando el cuadro se anima, cuando algo empieza a moverse entre sus límites, el espacio comienza a modelarse y a presentarse no ya como un conjunto estático, sino como una unidad plástica".

\subsection{El espacio significado}

El espacio, al contrario de lo que pueda parecer, no es un ente impersonal en muchos casos, sino que porta parcialmente la esencia de su morador o de lo que se sucede en su interior. En palabras de Sánchez Noriega (2000: 111) el texto fílmico "cobra entidad en función de su interrelación con los personajes; sin personajes el espacio carece de relieve y sin una relación estrecha solo aparece como un marco". Esta idea tiene que ver con la función metonímica a la que hace referencia Martínez García (2012), en la que el espacio está en relación con el personaje y no le es indiferente ni ajeno.

Así, en Arsénico por compasión, estos espacios determinantes de sentido se hacen perceptibles y se asocian de una manera concreta a la historia. Es el caso de la ubicación de la casa familiar: el hogar se encuentra emplazado justo al lado de un cementerio, el cual separa la casa de Mortimer Brewster y Elaine Harper. Los recién casados verán cómo la muerte, protagonista de la trama, es la culpable de su separación durante todo el texto fílmico.

Existen otros ejemplos de cómo el espacio se torna complejo por la transmisión de ideas. Cuando Jonathan Brewster llega a casa después de muchos años desaparecido, la casa familiar se transforma. Hasta su llegada, el espacio es luminoso y trans- 
mite ese tintineo proveniente de las conversaciones dicharacheras entre tía Abbey, tía Martha, Teddy, Mortimer y Elaine; hasta incluso la policía forma parte de los visitantes ocasionales que definen el espacio. En cuanto llega Jonathan acompañado de su secuaz, el Dr. Einstein, la iluminación se vuelve sombría, abundan las luces duras y las sombras. La casa se transforma en un espacio lúgubre adquiriendo así la personalidad de los nuevos inquilinos.

Por otro lado, también cabe destacar la creación de significados asociados a la parte alta de la casa, donde se encuentran las habitaciones, y la parte baja, el sótano. En el primer caso, la parte alta de la casa en la que se encuentra la habitación de Teddy y que enlaza perfectamente con la locura proveniente de su mente desequilibrada. Es ahí donde se viste de Roosvelt y donde cree conquistar la colina de San Juan encabezando un ejército durante una de las batallas acontecidas subiendo en realidad la escalera de su casa. Esto enlaza con el final de la película, cuando Mortimer trata de convencer a todos de que él también sufre trastornos mentales, emulando a su hermano Teddy subiendo la escalera y haciendo sonar la trompeta. Algo similar sucede con el sótano o "Canal de Panamá" en el que Teddy trabaja para ocultar los cadáveres de los hombres envenenados.

\section{Conclusiones}

El estudio del espacio narrativo y en concreto del cinematográfico dista mucho de ser una tarea sencilla. Por el contrario, es una labor compleja avalada por un amplio corpus teórico.

En cuanto a los objetivos planteados, se ha pretendido realizar un estudio pormenorizado del espacio para determinar su validez, buscando ejemplos concretos en el film estudiado que clarifiquen la exposición.

Si se atiende al primer objetivo, la distribución de los elementos en el espacio y al modo de representación utilizado para el desarrollo de la película, Arsénico por compasión presenta características que lo acercan a las representaciones escénicas. Como se exponía en un principio, es muy probable que sea fruto de la adaptación de la obra teatral homónima. De este modo, conserva muchas de las normas convencionales propias del teatro, lo que la convierte en texto audiovisual que ejemplifica el diálogo intermedial presupuesto.

Por otro lado, en los objetivos apuntados se pretendía observar la notabilidad del espacio fuera de campo. Tal y como se ha visto, éste toma gran relevancia en la trama, consiguiendo en diversas ocasiones más protagonismo incluso que el espacio visible para el espectador y mostrado dentro del cuadro. En este sentido, el espacio off se convierte en elemento imprescindible para el desarrollo narrativo equilibrando su peso con el espacio in. Existen numerosas secuencias que determinan la configuración del espacio en su conjunto como un elemento crucial en el desarrollo dramático.

Así pues, se muestra cómo el espacio permanece vivo y cambiante; ya que no solo adquiere rasgos característicos que permiten asociarlo con ideas concretas - personajes, situaciones o conflictos, entre otros - sino que además su idiosincrasia se puede ver modificada. Asimismo, es determinante la influencia que los personajes ejercen sobre el espacio al que pertenecen o del que se apropian al habitarlo de pronto. Dentro de los componentes narrativos, en esta obra en concreto, los movimientos de los personajes a través del espacio, tanto físico como simbólico, 
ayudan a definir la personalidad y peculiaridades propias de cada uno de ellos. De igual modo, que las propiedades del espacio quedan definidas por la interacción de todos los elementos narrativos.

Finalmente, se hace necesario precisar el innegable vínculo entre el espacio y el tiempo, unidos e influidos entre sí; dicho lo cual, el análisis se podría complementar en un futuro con un estudio del tiempo que daría una visión más completa de las dimensiones espacio-temporales de la obra.

\section{Bibliografía}

Aumont, Jacques, Bergala, Alain, Marie, Michel y Vernet, Marc. (2008). Estética del cine. Espacio, montaje, narración, lenguaje. Buenos Aires: Paidós.

Bazin, André. (1966). ¿Qué es el cine? Madrid: Ediciones Rialp.

Breijo, David. (1992). La locura según Capra: Arsénico por compasión. Vértigo. Revista de cine. (5): 42-43. Recuperado en: http://hdl.handle.net/10251/42957 (Fecha de acceso: 10/05/2019).

Bordwell, David y Thompson, Kristen. (1995). El arte cinematográfico: una introducción. Barcelona: Paidós Ibérica.

Burch, Nöel. (1999). El tragaluz del infinito: contribución a la genealogía del lenguaje cinematográfico. Madrid: Cátedra.

Burch, Nöel. (1970). Praxis del cine. Madrid: Fundamentos.

Casetti, Francesco y di Chio, Federico. (2017). Cómo analizar un film. 11ª impresión. Barcelona: Paidós Comunicación 172.

Chatman, Seymour. (1990). Historia y discurso: la estructura narrativa en la novela y en el cine Madrid: Taurus.

Cuadrado, Alfonso. (2014). "Tocar a través del cuadro: una genealogía del interfaz como metáfora de control en el espacio del arte, del cine y los videojuegos". Icono 14, volumen (12), pp. 141-167. doi: 10.7195/ri14.v12i2.708

Gallego-Díaz, Soledad. (2005, 15 de abril). “Arsénico por compasión”. El Pais. Recuperado en: https://elpais.com/diario/2005/04/15/cine/1113516012_850215.html (Fecha de acceso: $20 / 05 / 2019)$.

Gómez Tarín, Francisco Javier. (2003). Lo ausente como discurso: la elipsis y el fuera de campo en el texto cinematográfico. Tesis doctoral dirigida por Juan Miguel Company. Universidad de Valencia.

González Requena, Jesús. (1996). "Clásico, manierista, postclásico”. Área 5inco Revista de Comunicación Audiovisual y Publicitaria, $\mathrm{n}^{\circ}$ (5), pp. 81-121. País Vasco: UCM CAP I y CAP II, U.

Guarinos, Virginia. (1992). Teatro y televisión. Sevilla: Centro Andaluz de Teatro y Alfar.

Guarinos, Virginia. (1996). Teatro y cine. Sevilla: Padilla Libros.

Hernández Les, Juan A. (1993). Cine e literatura: a especificidade da imaxe visual. A Coruña: Xuna de Galicia.

IMDB en https://www.imdb.com/title/tt0036613/ (Fecha de consulta: 06/05/19).

Martínez García, María Ángeles. (2012). Laberintos narrativos: estudio sobre el espacio cinematográfico. Barcelona: Editorial Gedisa.

Mitry, Jean. (1978). Estética y psicología del cine. Madrid: Siglo XXI.

Neira, María del Rosario. (1998). "El espacio en el relato cinematográfico. Análisis de los espacios en un film". Archivum: Revista de la Facultad de Filología. Tomo 48-49, pp. 
373-397. Recuperado en https://dialnet.unirioja.es/servlet/articulo?codigo=2186513 (Fecha de consulta: 11/05/2019).

Pérez Bowie, José Antonio. (2004). "Teatro y cine: un permanente diálogo intermedial”. Arbor CLXXVII, 699-700 (Marzo-Abril), pp. 573-594 en http://arbor.revistas.csic.es/index. php/arbor/article/view/596/598 (Fecha de consulta: 24/04/2019).

Rollet, Patrice. (2014). "El espacio fílmico según Farber”. Cinema Comparat/ive Cinema, Vol. II, $n^{\text {o }}$ (4), pp. 69-73. Recuperado en http://www.ocec.eu/cinemacomparativecinema/ pdf/ccc04/ccc04_esp.pdf (Fecha de consulta: 23/04/2019).

Sánchez Noriega, José Luis. (2000). De la literatura al cine: teoría y análisis de la adaptación. Barcelona: Paidós Ibérica.

Xavier, Ismail. (2005). O discurso cinematográfico: a opacidade e a trasparência. $3^{\mathrm{a}}$ edicição. São Paolo: Paz e Terra. 